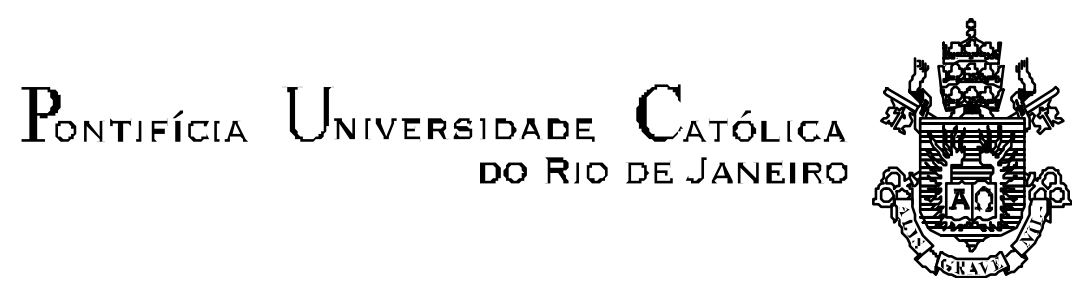

Flávia Vieira Santos

\title{
Transgressão melancolia e mal na Obra de Cornélio Penna
}

\author{
Tese de Doutorado
}

Tese apresentada ao Programa de Pós-graduação em Letras do Departamento de Letras da PUC/Rio como parte dos requisitos parciais para obtenção do título de Doutor em Letras.

Orientadora: Profa. Marília Rothier Cardoso

Rio de Janeiro

Março de 2008 


\section{Pontifícia $U_{\text {niversidade }}$ Católica $_{\text {aja }}$ \\ DO RIO DE JANEIRO}

Flávia Vieira Santos

\section{Transgressão, melancolia e mal na obra de Cornélio Penna}

Tese apresentada como requisito parcial para obtenção do grau de Doutor pelo programa de Pós-Graduação em Letras do Departamento de Letras do Centro de Teologia e Ciências Humanas da PUC-Rio. Aprovada pela Comissão Examinadora abaixo assinada.

Profa. Marília Rothier Cardoso

Orientadora

Departamento de Letras - PUC-Rio

Profa. Pina Arnoldi Coco

Departamento de Letras - PUC-Rio

Profa. Eneida Maria de Souza

UFMG

Pesquisador Visitante

Profa. Fátima Maria de Oliveira

PUC-Rio

Profa. Roberto Corrêa dos Santos

UFRJ

Prof. Paulo Fernando Carneiro de Andrade

Coordenador Setorial do Centro de Teologia e Ciências Humanas - PUC-Rio

Rio de Janeiro, de de 
Todos os direitos reservados. É proibida a reprodução total ou parcial do trabalho sem autorização da universidade, da autora e da orientadora.

Flávia Vieira Santos

Bacharel em Letras, Português-Literaturas pela UERJ (2001)

Mestre em Estudos de Literatura pela PUC-RIO (2003).

Ficha Catalográfica

Santos, Flávia Vieira
Transgressão melancolia e mal na obra de Cornélio
Penna / Flávia Viera Santos ; orientadora: Marília Rothier
Cardoso. - 2008.
262 f. : il. (color.) ; $30 \mathrm{~cm}$
Tese (Doutorado em Letras)-Pontifícia Universidade
Inclui bibliografia
1. Letras - Teses. 2. Literatura. 3. Melancolia. 4.
Feminino. 5. Modernismo. I. Cardoso, Marília Rothier. II.
Pontifícia Universidade Católica do Rio de Janeiro.
Debartamento de Letras. III. Título.

CDD: 800 


\section{Agradecimentos}

À CAPES, pela Bolsa sem a qual esse trabalho não teria sido possível.

À Marília Rothier Cardoso, pelas leituras minuciosas, afetuosas, pelas informações preciosas. E por abrir os caminhos assombrados do arquivo.

À família pelo apoio, pela paciência.

Ao Carlos, pelos mesmos motivos e pela ajuda na formatação.

Aos amigos, pelas conversas e sugestões.

À professora Jacqueline Penjon da Paris III - Sorbonne Nouvelle, pela orientação na França.

Aos amigos da Maison du Brèsil, pela intensa e frutífera convivência, principalmente Benedetta Pozzi e Tamima Mourad. 
"Toda verdadeira efígie tem sua sombra que a duplica; $e$ a arte sucumbe a partir do momento que o escultor que modela acredita liberar uma espécie de sombra cuja existência dilacerará seu repouso”. (Antonin Artaud) 


\section{Resumo}

Santos, Flávia Vieira; Cardoso, Marília Rothier (Orientadora). Transgressão, melancolia e mal na obra de Cornélio Penna. Rio de Janeiro, 2008. 262p. Tese de Doutorado - Departamento de Letras, Pontifícia Universidade Católica do Rio de Janeiro.

A tese se propõe a analisar a obra do escritor Cornélio Penna (1896-1958). Através do estudo de seus trabalhos - romances, pinturas e ilustrações - buscou-se a identificação de uma matriz melancólica que na referida obra, presentifica-se em todos esses registros. $\mathrm{O}$ trabalho também investiga os possíveis motivos do lugar marginal ocupado pela obra do autor no contexto do Modernismo Brasileiro, período no qual a maior parte de seus trabalhos teria sido produzida. Elegendo temas pouco explorados em sua época, tais como o feminino e a violência nos espaços familiares, a obra de Cornélio Penna permanece ainda hoje - passados setenta anos da publicação de seu primeiro livro - não só desconhecida do público em geral, mas também inclassificável no âmbito da literatura nacional.

\section{Palavras-chave}

Literatura, melancolia, feminino, Modernismo. 


\section{Abstract}

Santos, Flávia Vieira; Cardoso, Marília Rothier (Advisor). Transgression, melancholy, and evil in the work of Cornélio Penna. Rio de Janeiro, 2008. 262p. Doctoral Thesis - Departamento de Letras, Pontifícia Universidade Católica do Rio de Janeiro.

The purpose of the present study is to analyze the work of the Brazilian author Cornélio Penna (1896-1958). Through his work - novels, paintings and drawings - we have sought to identify a melancholic root that permeates the above registers. Our study also investigates possible reasons for the marginal position occupied by the author within Brazilian modernism, during which most of his work was produced. In choosing themes little explored at the time, such as the feminine, and violence within the family context, the work of Cornelio Penna remains today -70 years after the publication of his first book - not only little known to the public in general but difficult to classify within Brazilian literature.

\section{Keywords}

Brazilian literature, melancholy, feminine, Brazilian Modernism. 


\section{Indice}

$\begin{array}{ll}\text { Nota Introdutória } & 10\end{array}$

1. As primeiras explicações 12

1.1. Da dificuldade inicial 12

1.2. A construção de uma brasilidade obscura 18

1.3. Melancolia: A origem do termo 19

1.4. Uma melancolia solar? O medo e a $\quad 24$ sintomatologia do impasse

1.5. Melancolia e Ascedia: da afecção patológica à 28 "doença" espiritual

1.6. A melancolia e o descobrimento de uma 38 interioridade perturbada
A veiculação discursiva da melancolia: Benjamin e Freud

1.8. $\mathrm{O}$ discurso marcado pela melancolia: Freud 50

1.9. Melancolia: uma escolha diacrônica 58

1.10. $O$ discurso melancólico: as estratégias de 58 ocultamento e o segredo

2. A literatura e sua intrínseca relação com o Mal 61

2.1. Cornélio Penna e a escolha do Mal 64

2.2. O sacrifício: $O$ trágico, o religioso 72

2.3. A negação do feminino, primeiro caso: Eva 76

$\begin{array}{llll}\text { 2.4. A transgressão do feminino: segundo caso, } & 79\end{array}$ Medéia

2.5. As herdeiras de Medéia: quem são elas? 84

2.6. Literatura como contraface do Modernismo 86

2.7. O segredo, ou por onde a trama respira 90

2.8. Fingir: o corpo, o rosto: $o$ teatro 96

2.9. Primeiro caso: a máscara 97

2.10. Um intermezzo: a voz: como estrutura na qual 98 desliza o significante

2.11. Segundo caso: o corpo encerrado no privado, a 102 manifestação da doença

2.12. Aplicação da estratégia: levitar (a leveza, a 105 levitação)

3. A disposição do cenário; a casa paterna: Evocação de 108 Itabira

3.1. Fronteira: fervor religioso x loucura 112

3.2. Do teatro privado: artifício e disseminação da 118 violência

3.3. Do corpo supliciado: a evasão, a afirmação da 119 feminilidade pelo crime (pela transgressão) 
$\begin{array}{llllllll}\text { 3.4. Nico Horta: } & \text { O duplo e as duplicidades } & 128\end{array}$ fundamentais

3.5. Esaú e Jacó: fraternidade x rivalidade 131

3.6. $O$ caso Caim: isolamento $x$ progressividade 133

3.7. O caso Jó: ira x resistência pacífica 134

3.8. O caso Nico Horta: confluência de relatos 139

3.9. Suicídio $x$ esgotamento: o descondicionamento, a 143 escolha positiva

3.10. Repouso: a feminilidade irremediavelmente 152 ligada à transgressão

3.11. O duplo em Repouso: representação e evasão 154 pela via fabular

3.12. A virada de Dodote: da beleza decadente a 160 monstruosidade

3.13. Da preparação ao inumano: Thérèse 162 Desqueyroux, uma pequena digressão

3.14. O estado de exceção: a predisposição ao informe, 168 o crime e a rejeição da maternidade

4. Segundo cenário; a casa materna; A fazenda do 178 Grotão: Exortação à Pindamonhangaba

4.1. A menina morta: o segredo inconfessável, o 179 exercício da delicadeza

4.2. Presença do corpo forte: o corpo da opulência, o paradoxo do corpo que quer se insurgir contra a materialidade

4.3. Duas ou três palavrinhas sobre o silêncio, o segredo e a delicadeza (a feminilidade)

4.4. A preparação de Carlota: recuperação do 196 destino materno, desgoverno

4.5. Uma rainha e seu reino arruinado 200

5. A obra plástica de Penna: as cores da 203 tragicidade e da angústia

5.1. Uma linha imaginária entre Cornélio Penna e 216 Farnese de Andrade

5.2. $O$ mal de arquivo: o mal no arquivo 222

5.3. Do romance de antiquário ao arquivo 229 assombrado: o desenvolvimento da persona ficcional:

5.3.1. O primeiro episódio: a princesa da

5.3.2. O segundo episódio ou as visitas 231

5.3.3. $O$ terceiro episódio: dissabores à 235

5.4. O (último) exercício do colecionador: a 239 perversão da cronologia

5.5. Considerações finais: morte e difusão secreta 248

6. Bibliografia 


\section{Nota Introdutória}

A obra romanesca de Cornélio Penna é desconhecida não só do público em geral, mas também de boa parte dos interessados em literatura. A proposta de estudá- la surgiu a partir da leitura de seu último romance, A menina morta publicado em $1954 \mathrm{e}$ re-editado em 2001. Logo no início do projeto, surgiram os primeiros percalços referentes a estrangeiridade do domínio que se apresentava. Estrangeiridade esta, reafirmada a cada novo contato com os demais livros do autor: Fronteira, publicado em 1934, Dois romances de Nico Horta, em 1939, e Repouso, 1949.

Dos livros de Penna guarda-se, a princípio, um extremo desconforto, compatível somente com a impressão também assustadora suscitada por seus desenhos e pinturas aos quais o autor se dedicou antes de se voltar exclusivamente para literatura. Completando o mosaico formado pelos romances e pelos trabalhos plásticos de Penna tivemos acesso a alguns itens de seu arquivo, doados à Casa de Rui Barbosa pela esposa do autor, depois de sua morte. O conhecimento da obra plástica, e o acesso aos objetos do arquivo revelariam uma espécie de complementaridade entre as temáticas exploradas e os modos de expressão utilizados por ele. Autor de poucos leitores, Cornélio também passou quase desapercebido pela crítica. Foi este quase completo desconhecimento que permitiu alguma liberdade durante o processo da tese. Sendo assim, optou-se por identificar na obra de Penna uma intensa vinculação melancólica, uma incontestável envergadura maléfica, provenientes do que nos pareceu, desde o princípio, uma tentativa de acerto de contas com o passado que ele toma de empréstimo de seus pais, ao percorrer, pelos caminhos escarpados da memória, cidades mineiras e paulistas. Essa tentativa revisionista, direcionada a um passado não necessariamente seu, faz com que sua obra tenha se convertido num encontro, sem reservas, com uma série de memórias traumáticas devidamente convertidas por Cornélio em matéria de ficcionalização. 


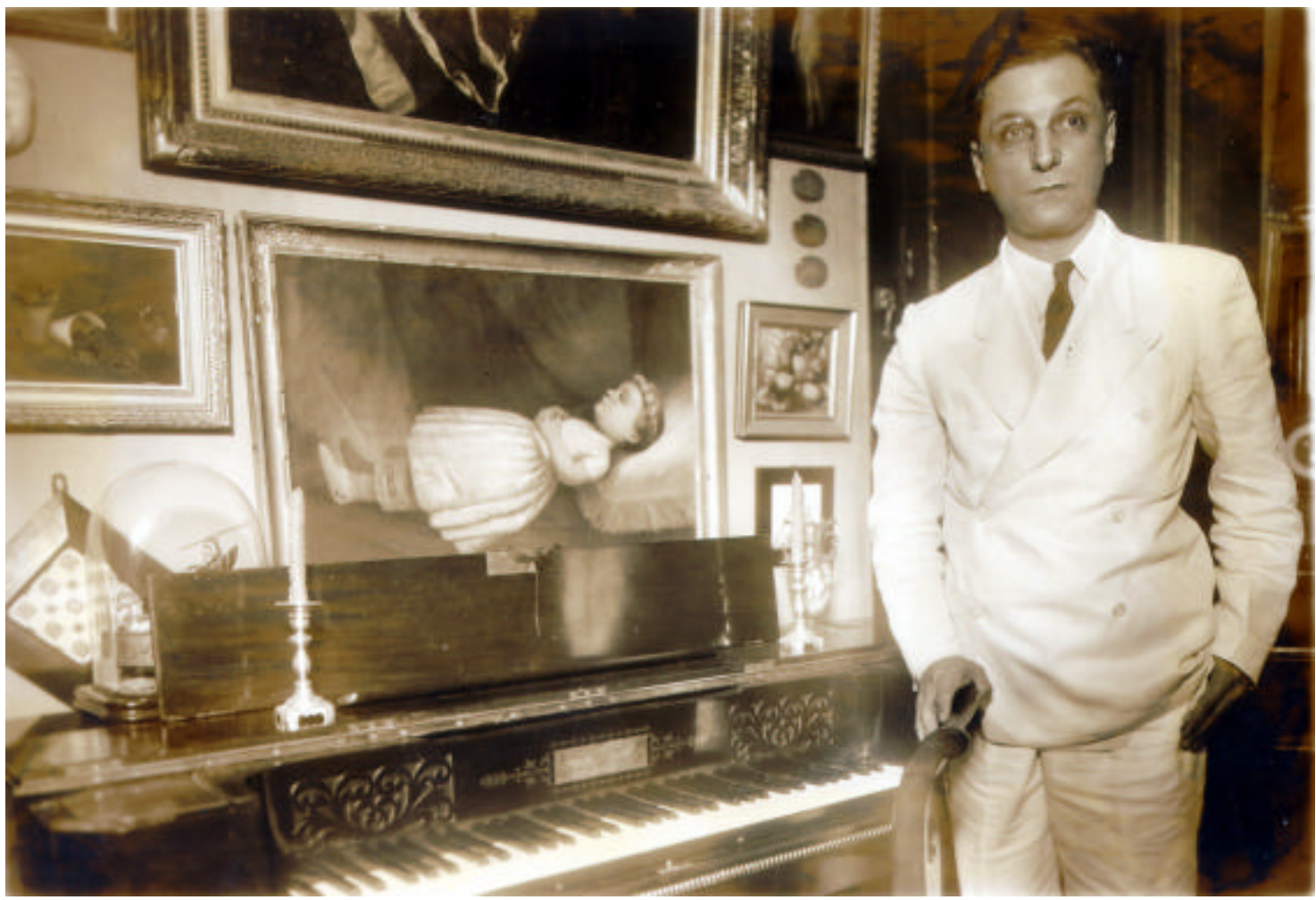

CORNÉLIO PENNA E O QUADRO DA MENINA MORTA 